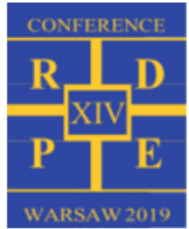

\title{
Investigation of off-design characteristics of solid oxide electrolyser (SOE) operated in endothermic conditions
}

\author{
Konrad M otylinski1,2, ${ }^{1}$, Michał W ierzbicki ${ }^{1,2}$, Stanisław Jagielski1,2, Jakub K upecki ${ }^{1,3}$ \\ ${ }^{1}$ D epartment of High Temperature Electrochemical Processes (HiTEP), Institute of Power Engineering, A ugustowka 36, 02-981 \\ Warsaw, Poland \\ 2 Institute of Heat Engineering, W arsaw U niversity of Technology, N ow owiejska 21/25, 00-665 W arsaw, Poland \\ ${ }^{3}$ National Fuel Cell Research Center (NFCRC), University of California, Irvine, Engineering L aboratory Facility, I rvine, California \\ 92697-3550, United States \\ * corresponding author: konrad.motylinski@ien.com.pl
}

\begin{abstract}
One of the key issues in the energy production sector worldwide is the efficient way to storage energy. Currently, more and more attention is focused on Power-to-Gas (P2G) installations, where excess electric power from the grid or various renewable energy sources is used to produce different kind of fuels, such as hydrogen. In such cases, generated fuels are treated as energy carriers which, in contrast to electricity, can be easy stored and transported. Currently, high temperature electrolysers, based solid oxide cells (SOC), are treated as an interesting alternative for P2G systems. Solid oxide electrolysers (SOE) are characterized as highly efficient $(\sim 90 \%)$ and long-term stable technologies, which can be coupled with stationary power plants. In the current work, the solid oxide cell stack was operated in electrolysis mode in the endothermic conditions. B ased on the gathered experimental data, the numerical model of the SOC stack was created and validated. The prepared and calibrated model was used for generation of stack performance maps for different operating conditions. The results allowed to determine optimal working conditions for the tested stack in the electrolysis mode, thus reducing potential costs of expensive experimental analysis and test campaigns.
\end{abstract}

\section{Introduction}

Currently more attention in power and energy sector is focused on minimizing the wide usage of fossil fuels, mainly due to their negative impact on the environment. At the same time, various solutions concerning power generation and efficient ways to storage energy are correlated with renewable energy sources (RES). The most commonly used technologies world-wide are solar and wind based power systems. The main issue with these solutions is dependence on local weather conditions, thus such energy sources are intermittent, which in many cases might by highly undesirable [1-3]. In response to that, many scientific and $R \& D$ entities are analysing different counter-solutions. M any specialists treats hydrogen as the gas of the future, which can be used as one of the main substrates in creating different and more calorific fuels, or directly convert it as the main power source for production of energy. This technologies are highly suggested for application in systems aiming to minimize pollution emissions to the atmosphere.

At present, steam reforming is the most commonly used method to generate hydrogen $[4,5]$, which is not a preferable solution in long-term perspective. As a result, in recent years new methods for efficient and clean hydrogen production are developed [6,7]. Steam electrolysis is currently considered as an preferable technology for application in mid- and large- scale hydrogen production installations, due to its high efficiency [8-10]. Among the existing electrolysers, commercially available and most advanced are alkaline and proton exchange membranes (PEM), which are used for low temperature electrolysis processes [11]. In recent years however, high temperature steam electrolysis based on solid oxide cells (SOC) proves to be a much better solution, due to lack of expensive catalysts and high hydrogen generation efficiency $(\sim 90 \%)[12,13]$. The comparison of performance between electrolysis technologies is presented in Fig. 1, showing polarization areas for specific device.

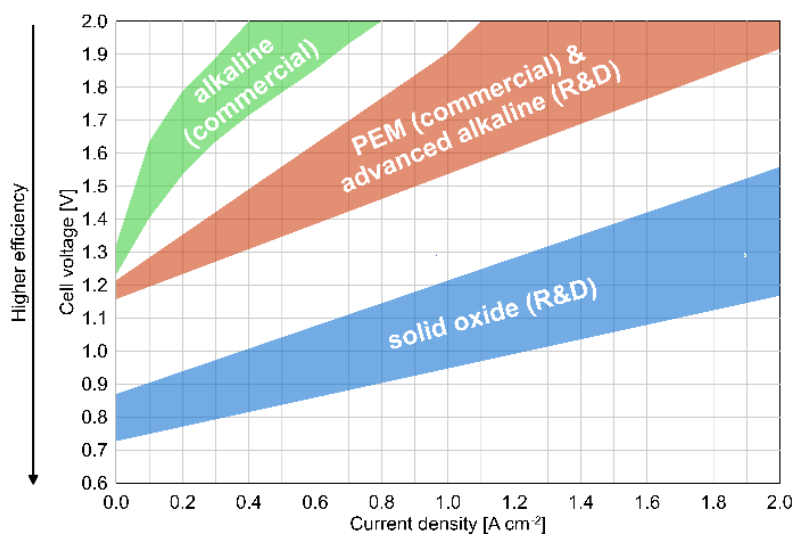

Fig. 1. State-of-the-art steam el ectrolysers (based on [13]). 
The performance of the electrolysers can be evaluated by comparing the need of electric power for the electrolysis reaction, generating the same amount of hydrogen. The operating areas presented in Fig. 1 show that high temperature electrolysers, based on solid oxide cells, require less power than low temperature technologies, thus their hydrogen production efficiency is higher. The difference is caused mainly by higher internal resistances between low- and high-temperature cells, hence the usage of the second technology might be more economically profitable in long-term perspective.

Solid oxide cells can operate as fuel cell which generates heat electric power or as an electrolyser for production of clean hydrogen and oxygen, when the specific conditions are met. Additionally, one of the main advantage of SOC-based technologies is the possibility to simply integrate them with existing stationary systems, either dedicated for production of electric power and heat or hydrogen [14].

Efficient way for storage of energy is currently an important and urgent topic in power sector world-wide. For that reason, more attention is dedicated for solutions that allows to both generate and distribute energy with minimization of potential losses. In such cases, electrolysers proves to be a preferable option, where generated hydrogen, treated as energy carrier, can be stored and transported for long distances. Systems with such topology are known as Power-to-Gas (P2G) installations where, besides hydrogen, methane and other, more calorific gases might be generated [15]. This concept can be further expanded by implementing proper chemical reactors, thus allowing to produce various liquid fuels (Power-to-Liquid (P2L)).

\section{High temperatures electrolysis}

W ater electrolysis reaction was discovered at the end of XIX century [16], but is still used in moderns technologies, such as in high temperature solid oxide electrolysers $(\mathrm{SOE})$. The operating temperature of SOE cells is from $600^{\circ} \mathrm{C}$ to $1000^{\circ} \mathrm{C}$, which is the result of used materials, such as $\mathrm{ZrO}_{2}$, for the electrolyte layer [14]. The steam electrolysis reaction is presented in Eq. 1:

$$
\begin{gathered}
\mathrm{H}_{2} \mathrm{O}_{(g)} \rightarrow \mathrm{H}_{2}+0.5 \mathrm{O}_{2} \\
\Delta H=247.9 \mathrm{~kJ} \cdot \mathrm{mol}^{-1}\left(\text { at } 750^{\circ} \mathrm{C}\right)
\end{gathered}
$$

where, $\Delta H$ is the reaction enthalpy. Operation of solid oxide electrolysers is shown in Fig 2.

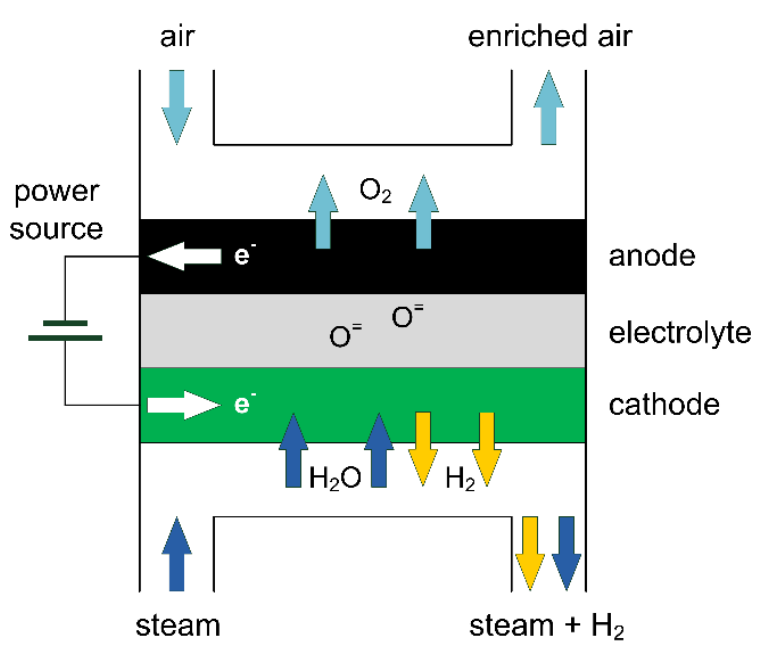

Fig. 2. SOE cell working principle.

Solid oxide cell consists of three different layers: cathode, anode and electrolyte. For the electrolysis operation, steam and electric power are delivered to the porous, fuel electrode. This results in reduction of water molecules for oxygen ions $\left(0^{2-}\right)$ and hydrogen in the cathode. Oxidant electrode is usually supplied with air but different gases might also be delivered or vacuum conditions might be applied, depending on the wanted SOE operation. In every case, oxidant molecules are formed on the anode side. The electrolyte is a thin layer which allows to pass only oxygen ions. Its structure has to be properly prepared in order to block diffusion of hydrogen and other, potential gases [17].

The SOE stack can operate in three different operating modes: thermo-neutral, endothermic and exothermic, which are strictly correlated with temperature and applied current $[18,19]$. During the electrolyser operation, part of electric power is used in the steam electrolysis reaction, while the rest is lost in from of the heat. As a result, temperature distribution in the stack depends on the compromise between the energy consumed by the reaction and the generated heat. When the amount of heat caused by the electric power exceed the required heat for the electrolysis reaction, the stack operates in the exothermic conditions, thus in-stack temperature rises. For the endothermic conditions, electrochemical reactions uses more heat than is delivered to the stack via electric current, thus lowering the stack operating temperature. In such case, additional heat needs to be delivered to the stack [20]. The switching point between exothermic and endothermic operation mode is known as the thermo-neutral voltage. Its value is dependent on the stack operating temperature and type of the electrolysis reaction, such as steam electrolysis, carbon dioxide electrolysis or mixed. Thermo-neutral voltage is calculated via Eq. 2, which is based on the Faraday's Law:

$$
E_{t h}=\frac{\Delta H}{n \cdot F}
$$


where, $\Delta H$ is the reaction enthalpy, $F$ is Faraday's constant and $n$ is the number of electrons needed in the reaction. For the steam electrolysis at $800^{\circ} \mathrm{C}$, the thermoneutral voltage is $1.28 \mathrm{~V}$.

Depending on the power system configuration with the installed SOE electrolyser, different operating modes are more preferable [21]. The main disadvantage of endothermal operation is need to deliver both heat and electricity for the electrolysis reaction. However, this can be compensated in case, where the SOE stack is connected to the external heat source. For the exothermal state, more electric current must be applied to the stack, which might result in damaging the cells in long-term operation. In the previous studies it was observed that for high currents in the electrolysis mode, the delamination of the oxidant electrode from the electrolyte layer might occur. In this process, interface of anode-electrolyte suffers build up of oxygen partial pressure, resulting in irreversible damage on the cell [22-24]. At the same time, high current affects the nickel-based cathode, which might suffer more rapid degradation [25-27]. As a result, stable and long-term operation of SOE-based systems, which is the aim for potential commercialization of the technology, is more difficult to achieve in exothermal state. For that reason, working in endothermal or near thermo-neutral conditions are more preferable.

In the current study, the numerical model of solid oxide electrolysis stack was designed and compared with gathered experimental data during endothermal operation of physical device. Next, the tuned model was used to generate stack performance maps for different operating conditions. The results allowed to determine optimal working conditions for the tested stack in the electrolysis mode, thus reducing potential costs of expensive test campaigns.

\section{Methodology}

The solid oxide electrolysis technology is under research and development for more than 40 years, but there are not many publications related to modelling of their operation both in stationary and transient cases. M ost of the SOE numerical tools are based SOFC mathematical methodologies, due to comparable mechanisms, such as gas diffusion and similar el ectrochemical behaviour. The proper SOFC modelling approach can be modified in order to simulate SOE operation [28-30].

In the chosen methodology for the present study, solid oxide cells electrical operation is calculated as equivalent electric circuit. This solution was already used to predict performance of SOFC-based power units both in steady state [31] and in transient operations [32]. In both cases, proposed methodology was validated and calibrated based on the experimental data, resulting in prediction error below $5 \%$. This concept was currently adopted for simulation of solid oxide electrolyser. The electric circuit equivalent of SOE is shown in Fig. 3.

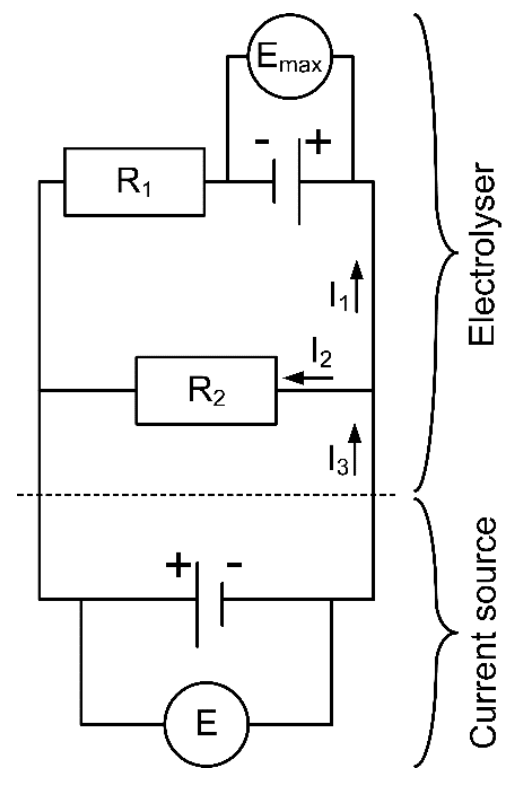

Fig. 3. Electric circuit equivalent of SOE.

In the proposed diagram, representing electrochemical cell operation, current delivered from the power source to the SOE is shown as $I_{3}$. Next, it is divided into flow of electrons used in the electrochemical reaction $\left(I_{1}\right)$ and $I_{2}$ which represents the total electronic conductivity.

In this approach, the voltage of the single cell is calculated by solving the electric circuit based on Ohm's and Kirchhoff's L aws :

$$
E_{\text {cell }}=\frac{E_{\max }+i_{\max } r_{1} \eta_{s}}{\frac{r_{1}}{r_{2}}\left(1-\eta_{s}\right)+1}
$$

where, $E_{\max }$ is the highest possible voltage obtained during isothermal process; $\eta_{s}$ is the steam utilization factor, which is defined by the current working conditions of the cell; $i_{\max }$ is the maximum current density correlated with amount of steam delivered to the cells; $r_{1}$ is the area specific internal ionic resistance representing oxygen ions permeability through the electrolyte and $r_{2}$ is the area specific internal electronic resistance which corresponds to solid el ectrolyte electric conductance. The full description of the used methodology is presented el sewhere [33].

In the current analysis, selected SOE module consists of two separated stacks, 30 cells each, as shown in Fig 4. 


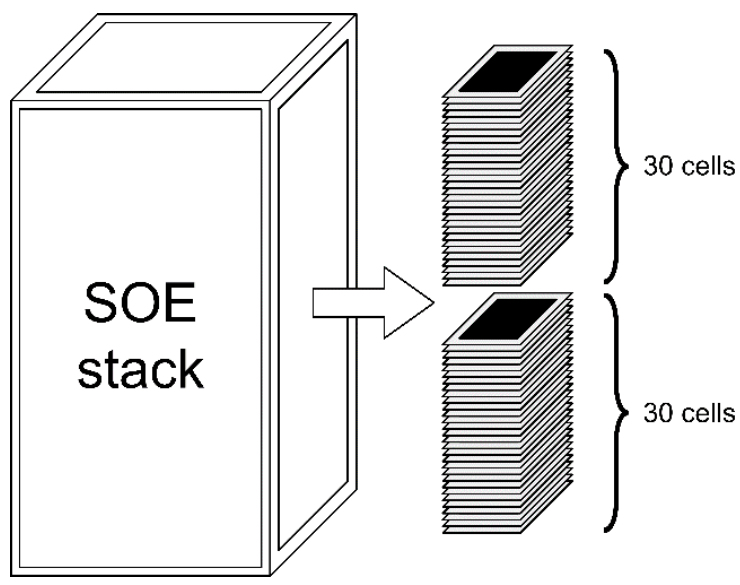

Fig. 4. SOE module concept.

The single stack contains 30 cells, where the cathode is porous NiO/GDC, the electrolyte is dense $3 \mathrm{YSZ}$ and the anode is double layered 8Y SZ/LSM-LSM. The active area of a single cell is $128 \mathrm{~cm}^{2}$. The chosen modeling approach includes technical specification of the stack, such as physical properties of the used materials for cells and interconnectors, thus minimizing the usage of empirical and semi-empirical constants and equations.

The model of the SOE stack was designed and implemented in Aspen Hysys modeling software. In order to properly simulate operating in the electrolysis mode, the proposed numerical tool was enhanced with additional in-house codes, which were determined based on the performed experiments with single cells and fullydimensional stack.

\section{Results}

The numerical model of the stack has undergone a validation process, based on the data gathered during measurements on the SOE module with two 30-cell stacks connected electrically in series. The experiments were performed in the electrolysis mode, operating mainly in the endothermic conditions.

The polarization curve of the SOE module was generated in constant $750^{\circ} \mathrm{C}$. In order to maintain stable temperature during measurements, proper power of inlet air heaters was set for each saved point. The validation of the proposed model is shown in Fig. 5.

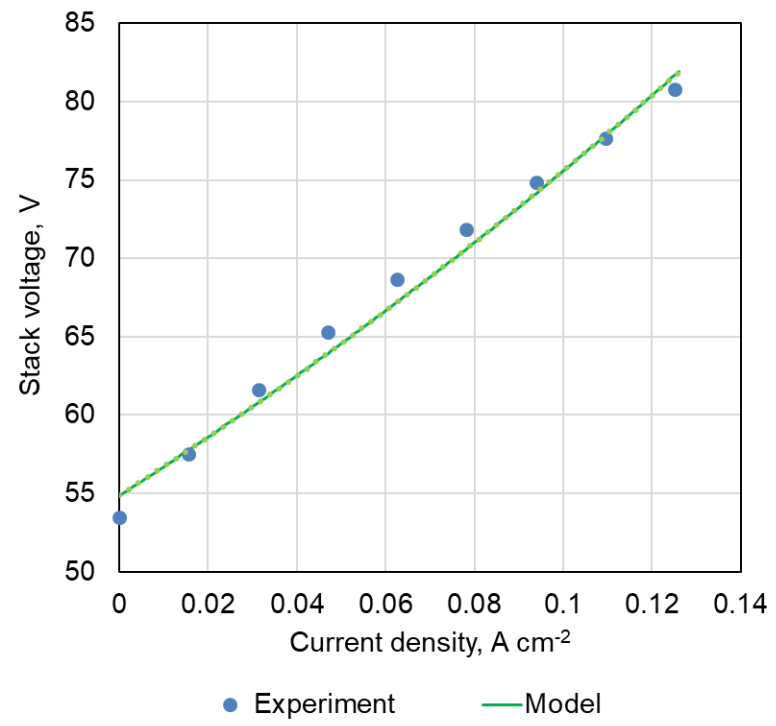

Fig. 5. M odel validation

The average prediction error was less than $1.41 \%$, where the relative prediction error did not exceed $3 \%$. While operating in the electrolysis mode, inlet gas for the cathode was composed of steam and additionally hydrogen and nitrogen, in order to maintain reductive atmosphere on the Nickel-based part of the cell. For the anode side, air was used as the oxidant.

Based on the known parameters and technical limitation of the stack, the validated model was used to generate performance maps of the SOE module. Such approach allows to determine optimal operating conditions for the stack, without having to realize expensive and time-consuming experimental campaigns. The main limiting factor included in the simulations is the maximum steam utilisation factor (SU), which shows the molar amount of steam used in water electrolysis reaction. There is no strict limiting value concerning SU reported in the available literature, but it is commonly assumed that $80 \%$ is the highest value [37].

In the realized numerical activities, two performance maps were generated for different input parameters: stack power and stack voltage. The amount of air and mixture of hydrogen and nitrogen were constant for every case. Due to the fact, that experimental analysis of the stack were performed only at $750^{\circ} \mathrm{C}$, the same temperature was used in the simulations. The only variables in the realized simulations were current density and flow of delivered steam. The obtained stack voltages and power are shown in Fig. 6 and 7, respectively. 


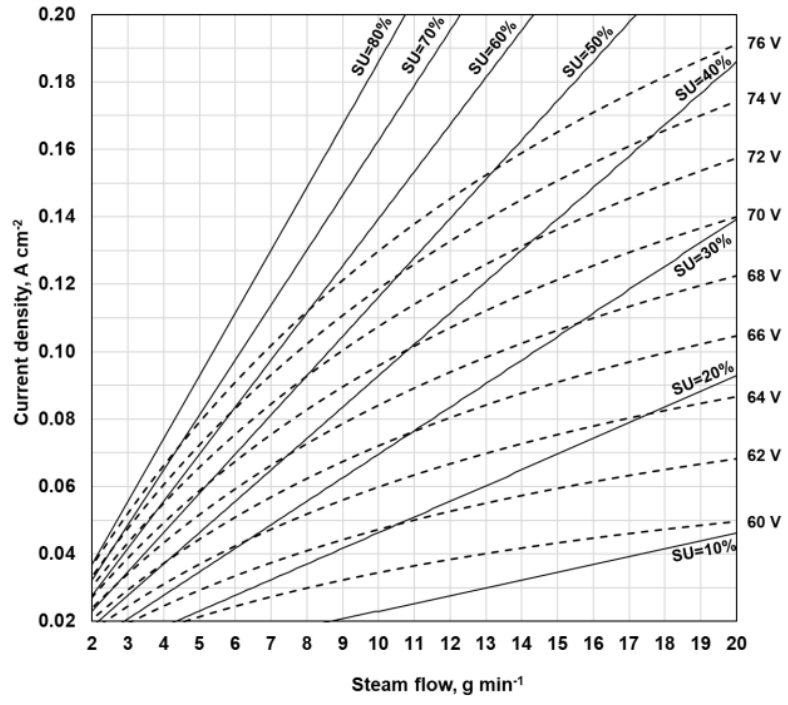

Fig. 6. SOE module performance map: voltage.

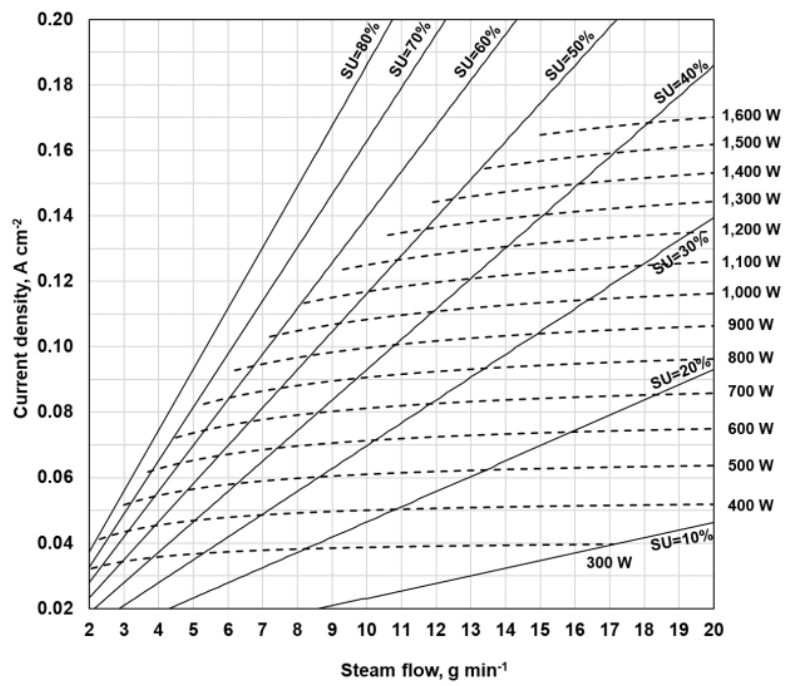

Fig. 7. SOE module performance map: power.

In order to operate in the endothermic conditions, maximal stack voltage was set to $76 \mathrm{~V}$, which corresponds to $\sim 1.27 \mathrm{~V}$ per cell. In Fig. 7, the dashed lines, representing different values of generated power, were presented only in the area which did not exceed $76 \mathrm{~V}$. Operating above this conditions, SOE module would work in exothermic mode, generating more heat than required for the electrolysis reaction, but resulting in potentially more rapid degradation of the cells.

\section{Conclusions}

In the current work, SOE module consisting of two stack with 30 cells each, was modelled and simulated in endothermic conditions. Operation below thermo-neutral point is more preferable solution compared to exothermic states, due to extended long-term durability of the stack and lower risks for degradation and potential damages in the cells. Based on the generated performance maps of the SOE module, it is possible to determine preferable operating conditions, depending on the wanted results. This allowed to perform simulations for different steam flows and current densities, without the need to realize expensive and long experimental campaigns. For the current study, SOE module was tested only in $750^{\circ} \mathrm{C}$. Further work in this topic will be dedicated in performing additional tests with the presented stacks in different operating temperatures. Obtained data will be used to further tune the proposed numerical model and generate additional performance maps, thus allowing to determine SOE module behaviour in wider operational range.

\section{Acknowledgment}

Authors acknowledge the financial support from the Ministry of Science and Higher Education of the Republic of Poland for Statutory Grant CPE/040/STAT/19 in the Institute of Power Engineering.

\section{References}

1. Ding Z., Hou H., Yu G., Hu E., Duan L., Zhao ., Performance analysis of a wind-solar hybrid power generation system, Energy Conversion and Management, V ol. 181, pp. 223-234, (2019).

2. Ma Z., Wang S., Li S., Shi Y., Long-term coordination for hydro-thermal-wind-solar hybrid energy system of provincial power grid, Energy Procedia, Vol. 158, pp. 6231-6235 (2019).

3. Salomone F., Giglio E., Ferrero D., Santarelli M., Pirone R., B ensaid S., Techno-economic modelling of a Power-to-Gas system based on SOE electrolysis and $\mathrm{CO} 2$ methanation in a RES-based electric grid, Chemical Engineering Journal, (2019), in press.

4. Balat M., Balat M., Political, economic and environmental impacts of biomass-based hydrogen, International Journal of Hydrogen Energy, V ol. 34, Issue 9, pp. 3589-3603, (2009).

5. Konieczny A., M ondal K., Wiltowski T., Dydo P., Catalyst development for thermocatalytic decomposition of methane to hydrogen, International Journal of Hydrogen Energy, V ol. 33, Issue 1, pp. 264-272, (2008).

6. Talawar M.B., Sivabalan R., Mukundan T., Muthurajan H., Sikder A.K., Gandhe B.R., Subhananda Rao A., Environmentally compatible next generation green energetic materials (GEM S), Journal of Hazardous Materials, V ol. 161, Issues 23, pp. 589-607, (2009).

7. $Y$ an $Y$., Fang Q., B lum L., Lehnert W ., Performance and degradation of an SOE stack with different cell components, Electrochimica Acta, Vol. 258, pp. 1254-1261, (2017).

8. Bo $Y$., W enqiang $Z$., J jingming $X$., Jing $C$., Status and research of highly efficient hydrogen production through high temperature steam electrolysis at INET, International Journal of Hydrogen Energy, Vol. 35, Issue 7, pp. 2829-2835, (2010).

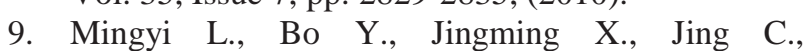
Thermodynamic analysis of the efficiency of hightemperature steam electrolysis system for hydrogen production, Journal of Power Sources, V ol. 177, Issue 2, pp. 493-499, (2008). 
10. Li Q., Zheng Y., Guan W., J in L., Xu C., Wang W.G., Achieving high-efficiency hydrogen production using planar solid-oxide electrolysis stacks, International Journal of Hydrogen Energy, V ol. 39, Issue 21, pp. 10833-10842, (2014).

11. Mocoteguy P., Brisse A., A review and comprehensive analysis of degradation mechanisms of solid oxide electrolysis cells, International Journal of Hydrogen Energy, V ol. 38, Issue 36, pp. 15887-15902, (2013).

12. Fang Q., Blum L., M enzler N.H., Performance and Degradation of Solid Oxide Electrolysis Cells in Stack, Journal of The Electrochemical Society, Vol. 162, Issue 8, pp. F907-F912, (2015).

13. Graves C., Ebbesen S.D., Mogensen M., Lackner K.S., Sustainable hydrocarbon fuels by recycling $\mathrm{CO} 2$ and $\mathrm{H} 2 \mathrm{O}$ with renewable or nuclear energy, Renewable and Sustainable Energy Reviews, Vol. 15, Issue 1, pp. 1-23, (2011).

14. Gruber M., Wienbrecht P., Biffar L., Harth S., Trimis D., Brabandt J., Posdziech O., Blumentritt R., Power-to-Gas through thermal integration of high-temperature steam electrolysis and carbon dioxide methanation - Experimental results, Fuel Processing Technology, Vol. 181, pp. 61-74, (2018).

15. Nielsen S., Skov I.R., Investment screening model for spatial deployment of power-to-gas plants on a national scale - A Danish case, International Journal of Hydrogen Energy, V ol. 44, Issue 19, pp. 9544-9557, (2018).

16. $Y$ an $X . L .$, Hino R., Nuclear hydrogen production handbook. Green Chemistry and Chemical Engineering, CRC Press, 1st edition, (2016).

17. $\mathrm{Ni}$ M., Leung M.K.H., Leung D.Y.C., Technological development of hydrogen production by solid oxide electrolyser cell (SOE), International Journal of Hydrogen Energy, Vol. 33, Issue 9, pp. 2337-2354, (2008).

18. Navasa M ., Y uan J ., Sunden B ., Computational fluid dynamics approach for performance evaluation of a solid oxide electrolysis cell for hydrogen production, Applied Energy, Vol. 137, pp. 867-876, (2015).

19. Udagawa J., A guiar P., Brandon N.P., Hydrogen production through steam electrolysis: Model-based dynamic behaviour of a cathode-supported intermediate temperature solid oxide electrolysis cell, Journal of Power Sources, V ol. 180, Issue 1, pp. 46-55, (2008).

20. Petipas F., Brisse A., B ouallou C., Model-based behaviour of a high temperature electrolyser system operated at various loads, Journal of Power Sources, Vol. 239, pp. 584-595, (2013).

21. Santhanam S., Heddrich M .P., Riedel M., Friedrich K.A., Theoretical and experimental study of Reversible Solid Oxide Cell ( $r$-SOC) systems for energy storage, Energy, Vol. 141, pp. 202-214, (2017).

22. Virkar A.V., Mechanism of oxygen electrode delamination in solid oxide electrolyser cells. International, Journal of Hydrogen Energy, V ol. 35, Issue 18, pp. 9527-9563, (2010).
23. Sun $X .$, Chen M., Liu Y.L., Hendriksen P.V., Life Time Performance Characterization of Solid Oxide Electrolysis Cells for Hydrogen Production, ECS Transactions, Vol. 68, Issue 1, pp. 3359-3368, (2015).

24. Sun $X_{\text {., }}$ Chen M., Liu $Y . L .$, Hjalmarsson $P_{\text {., }}$ Ebbesen S.D., Jensen S.H., Mogensen M.B., Hendriksen P.V., Durability of Solid Oxide Electrolysis Cells for Syngas Production, Journal of the Electrochemical Society, Vol. 160, Issue 9, pp. F1074-F1080, (2013).

25. Tietz F., Sebold D., Brisse A., Schefold J., Degradation phenomena in a solid oxide electrolysis cell after $9000 \mathrm{~h}$ of operation, Journal of Power Sources, Vol. 223, pp. 129-135, (2013).

26. Chen M., Sun X., Chatzichristodoulou C., Koch S., Hendriksen P.V., Thermoneutral Operation of Solid Oxide Electrolysis Cells in Potentiostatic Mode, ECS Transactions, Vol. 78, Issue 1, pp. 3077-3088, (2017).

27. Hoerlein M .P., Schiller G., Tietz F., Friedrich K.A., Systematic Parameter Study on the Influence of Humidification and Current Density on SOEC Degradation, ECS Transactions, Vol. 68, Issue 1, pp. 3553-3561, (2015).

28. Njodzefon J.C., Klotz D., Kromp A., Weber A., Ivers-Tiffee E., Electrochemical Modeling of the Current-V oltage Characteristics of an SOFC in Fuel Cell and Electrolyser Operation Modes, Journal of The Electrochemical Society, Vol. 160, Issue 4, pp. F313-F 323, (2013).

29. Petipas F., Grisse A., B ouallou C., Model-based behaviour of a high temperature electrolyser system operated at various loads, Journal of Power Sources, Vol. 239, pp. 584-595, (2013).

30. Iora P., Chiesa P., High efficiency process for the production of pure oxygen based on solid oxide fuel cell-solid oxide electrolyser technology, Journal of Power Sources, Vol. 109, Issue 2, pp. 408-419, (2009).

31. K upecki J., Off-design analysis of a micro-CHP unit with solid oxide fuel cells fed by DME, International Journal of Hydrogen Energy, $\mathrm{V}$ ol. 40, Issue 35, pp. 12009-12022, (2015).

32. Kupecki J., et al., Dynamic numerical analysis of cross-, co-, and counter-current flow configurations of a $1 \mathrm{~kW}$-class solid oxide fuel cell stack, International Journal of Hydrogen Energy, V ol. 40, Issue 45, pp. 15834-15844, (2015).

33. Milewski J., Świrski K., Santarelli M., Leone P., Advanced methods of solid oxide fuel cell modeling, Green Energy Technology, Springer, (2014).

34. Iora P., Taher M .A.A., Chiesa P., B randon N.P., A novel system for the production of pure hydrogen from natural gas based on solid oxide fuel cell-solid oxide electrolyser, International Journal of Hydrogen Energy, Vol. 35, Issue 22, pp. 1268012687, (2010).

35. Cai Q., L una-Ortiz E., A djiman C.S., Brandon N.P., The Effects of Operating Conditions on the Performance of a Solid Oxide Steam Electrolyser: A 
M odel-Based Study, Fuel Cells From Fundamentals to Systems, V ol. 10, Issue 6, pp. 1114-1128, (2010).

36. Kim J.S., Boardman R.D., Bragg-Sitton S.M., Dynamic performance analysis of a hightemperature steam electrolysis plant integrated within nuclear-renewable hybrid energy systems, Applied Energy, V ol. 228, pp. 2090-2110, (2018).

37. Wang Z., Mori M., A raki T., Steam electrolysis performance of intermediate-temperature solid oxide electrolysis cell and efficiency of hydrogen production system at $300 \mathrm{Nm} 3 \mathrm{~h}-1$, International Journal of Hydrogen Energy, V ol. 35, Issue 10, pp. 4451-4458, (2010). 